\title{
Correlation of ergonomic risk factors with RULA in IT professionals from India
}

\author{
Deepak Sharan ${ }^{1}$ and Ajeesh P S ${ }^{1}$. \\ ${ }^{1}$ RECOUP Neuromusculoskeletal Rehabilitation Centre, Bangalore, INDIA
}

\begin{abstract}
Work-related musculoskeletal disorders (WMSD) are common in computer professionals worldwide. Studies have shown that there is an association between the working posture and the development of musculoskeletal disorders. The IT professionals are exposed to different awkward posture while working. Therefore, it is expected that workers may develop different kinds of musculoskeletal discomfort/pain. This study aimed at to find out the relationship between the musculoskeletal discomfort and the postural score. RULA was used for postural analysis. Results of the postural analysis revealed that $30 \%$ of the participant's posture need to "modify soon" and $15 \%$ need to modify "immediately". $78 \%$ of the participants were using computer for more than 8 hours in a day. The major workstation risk factors were reported as improper keyboard height and mouse tray height (32\%), improper monitor height (27\%) and improper chair height (12\%). Results also revealed a significant association between the regional body pain and the RULA score. Musculoskeletal pain was significantly associated with workstation keyboard/mouse surface $(\mathrm{r}=0.55)$ and duration of computer use $(\mathrm{r}=0.64)$. Intervention programme was recommended for the participant to modify the workstation and the working posture.
\end{abstract}

Keywords: workstation Information, RULA, pain

\section{Introduction}

Now a day's use of computer is substantially increased. Studies have shown that $56 \%$ of workers use computers on the job and $62 \%$ of households own a computer [8]. Work-related musculoskeletal disorders (WMSD) are common in computer professionals. Literature says that the occupation which is at the high risk of neck - shoulder pain; is use of computer [4, 7, 15]. Intensive use of computer in the workstation is the major well known factor for the development of work related musculoskeletal disorders and the sick leave which affects physical health of the workers, impose financial burden on the employers and family and social life of the affected person [17]. It has been found that WRMSDs associated with numerous occupational risk factors, including physical work load factors such as force, posture, movement and vibration [12], psychosocial stressors [3] and individual factors [2] which are also known to be important as predictive variables. In India, approximately $76 \%$ of computer professionals reported symptoms of musculoskeletal discomfort in various epidemiological studies [9, 21].
Among the associated risk factors of work relate musculoskeletal disorders awkward working posture plays a major role. The prevalence of musculoskeletal disorders amongst keyboard users has been reported to be as high as $81 \%$ [14]. Studies have shown that awkward posture is strongly associated with the development of musculoskeletal problems. On the contrary there are studies which revealed that there is no association between posture and development of MSD. Postural analysis can be done using different technique. Among all the technique RULA is reliable and valid for evaluating the posture which involve upper limb. The IT professional normally sits in table chair arrangement and the work involves upper limb. The aim of this study was to examine the correlation of ergonomic and postural risk factors with Rapid Upper Limb Assessment (RULA) associated with computer work in Indian IT professionals.

\section{Method}

The data presented in this study was extracted from various IT professionals who were a part of

Corresponding author: deepak.sharan@recoup.in

${ }^{1}$ Address: \#312, 80 Feet Road, 10th Block, Further Extension of Anjanapura Layout, Bangalore-560062, India 
Ergonomic workplace evaluation organized by their company. Data was extracted from 620 individuals. The assessment was performed by RECOUP Neuromusculoskeletal Rehabilitation Centre at the company premises. The data collected consisted of demographics such as age, gender, height, weight, Laptop/Desktop used, and working hours. A structured questionnaire was administered to evaluate the workstation components such as seating, keyboard/input device, monitor, and working surface. Working posture was evaluated using rapid upper limb assessment (RULA), which is known as pen-paper observational method [19]. According to this method a score is calculated for the posture of each body part. A score of 1 indicated the best or most neutral posture. A score of 4 indicated the worst position, Muscle use and force exerted in each position were attributed a score of 0 and 1. Whereas low grand scores of 1 or 2 indicate that the work posture is acceptable, for grand score of 3 or 4 indicate further investigation and changes if required, prompt investigation and changes for grand scores of 5 or 6 and immediate investigations and changes for a grand score of 7 . Self reported body part discomforts were also evaluated while working.

\subsection{Data analysis}

Participant demographic characteristics are summarized in Table 1 and Table 2 . In order to understand which ergonomic risk factors with RULA relate to pain, non-parametric correlation analysis was conducted using Spearman Rank order correlation coefficients. The factors included were RULA scores, Workstation information, gender, duration of computer use per day and pain score of various body parts. Statistical analyses were conducted using the SPSS version18.0 with a significance level set at $\mathrm{p}<0.05$ for all tests.

\section{Result}

\subsection{Prevalence}

Six hundred and twenty participants' data was extracted from the database. The average age, height and weight of the participants are represented in (Table 1).

Table 1.

Mean and Standard Deviation of the Participant

\begin{tabular}{lc}
\hline Sample Size(N) & $\mathbf{6 2 0}$ \\
\hline Age(years) & $28.45 \pm 10.4$ \\
Height $(\mathrm{cm})$ & $163.45 \pm 9.35$ \\
Weight $(\mathrm{kg})$ & $61.45 \pm 7.44$ \\
\hline
\end{tabular}

Descriptive analysis of the demographic data indicated that the majority $(75 \%)$ of respondents were females (Table 2). $78 \%$ of participants worked more than 8 hours on a computer and 55\% used a desktop computer.

Table 2.

Participants Demographics

\begin{tabular}{|c|c|}
\hline Category & Percentage \\
\hline \multicolumn{2}{|l|}{ Gender } \\
\hline Male & $25 \%$ \\
\hline Female & $75 \%$ \\
\hline \multicolumn{2}{|c|}{ Technology used } \\
\hline Desktop & $55 \%$ \\
\hline Laptop & $28 \%$ \\
\hline Both & $17 \%$ \\
\hline \multicolumn{2}{|c|}{ Duration of computer use per day } \\
\hline$<6$ hours & $1 \%$ \\
\hline $6-8$ hours & $21 \%$ \\
\hline$>8$ hours & $78 \%$ \\
\hline
\end{tabular}

Workstation evaluation revealed that $12 \%$ participants were using improper chair height. $32 \%$ of participants had improper keyboard and mouse tray height, $27 \%$ of participants worked on a monitor, which was higher than the eye level and $16 \%$ of participants had improper writing surface. Observation also revealed that $78 \%$ of Laptop users did not utilize external keyboard and mouse. The 
result of postural analysis revealed that $65 \%$ of participants were under action level 2, which requires further investigation and changes may be required. $30 \%$ of participants were under action level 3, which indicates that changes are needed soon. $15 \%$ of participants were under action level 4, which indicates changes are needed immediately (Table 3).

Table 3.

\begin{tabular}{lc} 
& Result of Postural analysis \\
\hline Action Level & Percentage \\
\hline Action Level 2 & $65 \%$ \\
Action Level 3 & $30 \%$ \\
Action Level 4 & $15 \%$ \\
\hline
\end{tabular}

\subsection{Correlation}

Correlation Analyses revealed that pain was significantly correlated with RULA neck score $(\mathrm{r}=0.49, \mathrm{p}=0.004)$, Upper $\operatorname{arm}(\mathrm{r}=0.46, \mathrm{p}=0.004)$ and wrist $(\mathrm{r}=0.67, \mathrm{p}=0.005)$ subscale. Pain was also significantly correlated with Workstation keyboard/ mouse Surface $(r=0.64, p=0.005)$, writing Surface $(r=0.54, p=0.005)$, and Monitor Height $(\mathrm{r}=0.55, \mathrm{p}=0.005)$, and duration of computer $(r=0.64, p=0.005)$. There is Significant correlation between the Ergonomic workstation risk factors and RULA posture Score $(r=0.67, p$ $=0.005$ ).

\section{Discussion}

Studies have shown that prolonged activation of muscle fibers during low-level contractions such as typing may result in fatigue and increase pain sensitivity [21]. Literature also revealed that awkward posture lead to the development of musculoskeletal discomfort / pain [19]. In the present study, the working posture of the IT professional most of the cases were at Action level 2 which indicate the changes may require. $15 \%$ participants were at the level 4 which means the postures that they adopted were not at all conducive and it requires change immediately. The development of musculoskeletal disorders among the IT professional may be due to this awkward posture adopted by them during their working schedule. Studies have reported that use of computer for more than three hours a day is hazardous $[1,20]$. The participants of the present study work more than eight hours per day in computer. This long duration of exposure may also lead to the development of musculoskeletal discomfort/pain among the IT professional which is corroborated with the result of relationship between the working hours and the responses of pain/discomfort. In this study, there is a Significant correlation between the RULA posture Score, Workstation risk factors like improper Chair height, Keyboard / mouse Surface, Writing Surface, Monitor Height and the musculoskeletal pain experienced by the patient. A number of recent studies have reported that mouse use commonly involves work postures associated with musculoskeletal disorders $[5,13,16]$. Studies further reported that mouse users experienced higher muscular loading on the anterior deltoid muscle and lower loading on the upper trapezius muscle, compared with keyboard users [6]. The position of the mouse away from the midline of the body results in mouse users working with the arm unsupported, the shoulder abducted and externally rotated and the arm in forward flexion [10, 11]. Present study result revealed $51 \%$ of participants had improper keyboard and mouse tray height. This may be the reason for the development of musculoskeletal disorders and pain. The participants were recommended postural correction to reduce or minimize the risk of the development of work related musculoskeletal disorders. Further study is needed to conduct a detailed analysis of risk factors for the development of musculoskeletal disorders among IT professional.

\section{Conclusion}

This study highlighted the correlation of Pain and the RULA neck, Upper arm and wrist postural score adopted in IT professionals. Ergonomic interventions through corrective measures could be taken into account for reducing exposure level and consequently preventing WRMSDs is highly recommended by performing workers training on working posture, administrative measures for 
establishing work-rest cycle, using proper seats which equipped with backrest together with reducing the height of working table in accordance to anthropometric data.

\section{Reference}

[1] Aaras A., Fostervold, K., Ro, O., Thoresen, M., Larsen, S., Postural load during VDU work: a comparison between various work postures, Ergonomics, 1997, 40, 1255 - 1268.

[2] Armstrong T.J., Buckle P., Fine L.J., Hagberg M., Jonsson B., Kilbom A.Ê., Kuorinka I.A.A., Silverstein B.A., Sjogaard G. and Viikari-Juntura E.R.A., A conceptual model for work related neck and upper-limb musculoskeletal disorders, Scand J. Work Environ. Health, 1993, 19, $73-84$

[3] Bongers P.M., Dewinter C.R., Kompier M.A.J. and Hildebrandt V.H., Psychosocial factors at work and musculoskeletal disease, Scand J. Work Environ. Health, 1993, 19, $297-312$.

[4] Bureau of Labor Statistics. Computer and Internet use at work in 2003. Washington, DC: United States Department of Labor, 2005.

[5] Cook C., Kothiyal K., Influence of mouse position on muscular activity in the neck, shoulder and arm in computer users, Applied Ergonomics, 1998, 29, 439 - 443.

[6] Cooper A., Straker L., Mouse versus keyboard use: a comparison of shoulder muscle load, International Journal of Industrial Ergonomics, 1988, 22, $351-357$.

[7] Cote P, van der Velde G., Cassidy J.D., Carroll L.J., HoggJohnson S., Holm L.W., Carragee E.J., Haldeman S., Nordin M., [8] Hurwitz E.L., Guzman J., Peloso P.M., The burden and determinants of neck pain in workers - Results of the bone and joint decade 2000-2010 task force on neck pain and its associated disorders, Spine, 2008, 33 , 60-74.

[9] Day J.C., Janus A., Davis J., Computer and Internet use in the United States: 2003. Washington, DC: US Department of Commerce, 2005.

[10] Eltayeb S., Staal J., Hassan A., and de Bie R., Work Related Risk Factors for Neck, Shoulder and arm Complaints: A Cohort Study among Dutch Computer Office Workers, Journal of Occupational Rehabilitation, 2009, 19, 315-322

[11] Fernstrom E., Ericson M.O., Computer mouse or trackpoint- effects of muscular load and operator experience, Applied Ergonomics, 1997, 28, 347 - 354.

[12] Franzblau A., Flaschner D., Albers J.W., Blitz S., Werner R., Armstrong T., Medical screening of o\$ce workers for upper extremity cumulative trauma disorders, Archives of Environmental Health, 1993, 48, $164-170$.

[13] Gerr F., Letz R. and Landrigan P.J., Upper extremity musculoskeletal disorders of occupational origin, Ann. Rev. Pub. Health, 1991, 12, 543 - 566.

[14] Harvey R., Peper E., Surface electromyography and mouse use position, Ergonomics 1997, 4, $781-789$.
[15] Kamwendo K., Linton S.J., Moritz U., Neck and shoulder disorders in medical secretaries, Scandinavian Journal of Rehabilitation Medicine, 1991, 23, 127 - 133.

[16] Karlqvist L., Hagberg M., Koster M., Wenemark M., Anell R., Musculoskeletal symptoms among computer assisted design (CAD) operators and evaluation of a selfassessment questionnaire, International Journal of Occupational and Environmental Health, 1996, 2, 185 194.

[17] Karlqvist L., Hagberg M., Selin K., Variation in upper limb posture and movement during word processing with and without mouse use, Ergonomics, 1994, 37, 1261 - 1267.

[18] Korhan O. and Mackieh , An empirical investigation of the detrimental effects of the intensive use of computers in the business world, African Journal of Business Management 2011, 5, 656-665.

[19] Leuder R., A proposed RULA for computer users. Paper presented at the Ergonomic Summer Workshop, San Francisco, 1996

[20] Mohammad P., Mehdi A. and Kamal A., Investigation of Risk Factors of Work-Related Upper-Limb Musculoskeletal disorders in a Pharmaceutical Industry, Journal of Applied Sciences, 2008, 8, 1262 - 1267.

[21]Richardson S., and Tan E.M., Mmanagers under stress in Singapore, Int. J. Ind. Ergonom, 1986, 1, 115 - 126.

[22] Sjogaard G., and Jensen B, Muscle pathology with overuse. In D. Ranney (Ed.), Chronic Musculoskeletal Injuries in the Workplace, Philadelphia, PA: W.B. Saunders Company 1997, $17-40$. 